\title{
Expansion of organic Rankine cycle working fluid in a cylinder of a low-speed two-
} stroke ship engine

\author{
Larsen, Ulrik; Wronski, Jorrit; Andreasen, Jesper Graa; Baldi, Francesco; Pierobon, Leonardo
}

\author{
Published in: \\ Energy
}

Link to article, DOI:

10.1016/j.energy.2016.11.069

Publication date:

2017

Document Version

Peer reviewed version

Link back to DTU Orbit

Citation (APA):

Larsen, U., Wronski, J., Andreasen, J. G., Baldi, F., \& Pierobon, L. (2017). Expansion of organic Rankine cycle working fluid in a cylinder of a low-speed two-stroke ship engine. Energy, 119, 1212-1220.

https://doi.org/10.1016/j.energy.2016.11.069

\section{General rights}

Copyright and moral rights for the publications made accessible in the public portal are retained by the authors and/or other copyright owners and it is a condition of accessing publications that users recognise and abide by the legal requirements associated with these rights.

- Users may download and print one copy of any publication from the public portal for the purpose of private study or research.

- You may not further distribute the material or use it for any profit-making activity or commercial gain

- You may freely distribute the URL identifying the publication in the public portal 


\title{
Expansion of organic Rankine cycle working fluid in a cylinder of a low-speed two-stroke ship engine
}

\author{
Ulrik Larsen $^{\mathrm{a}, *}$, Jorrit Wronski ${ }^{\mathrm{b}}$, Jesper Graa Andreasen $^{\mathrm{c}}$, Francesco Baldi $^{\mathrm{a}}$, Leonardo Pierobon ${ }^{\mathrm{c}}$ \\ ${ }^{a}$ Chalmers University of Technology, Shipping and Marine Technology, SE-412 96 Gothenburg, Sweden \\ ${ }^{b}$ IPU, Building 403, Nils Koppels Allé, 2800 Kgs. Lyngby, Denmark \\ ${ }^{c}$ Section of Thermal Energy, Department of Mechanical Engineering, Technical University of Denmark, \\ Building 403, Nils Koppels Allé, 2800 Kgs. Lyngby, Denmark
}

\begin{abstract}
Electricity and power produced from waste heat is particularly relevant in shipping because fuel expenses constitute the majority of the cost of operating the ships; however, the cost-benefit aspect limits the widespread implementation of waste heat recovery power units on ships. This paper presents the thermodynamic analysis of a concept that aims at reducing the cost of an organic Rankine cycle unit by using one of the cylinders in a large diesel engine as expansion device. Numerical models were used to optimise the process parameters and thereby determine the power potential for this concept. The evaluation of 104 working fluids points to cyclopropane, R245fa and R1234ze(z) as the most promising. The results suggest that the power produced by the organic Rankine cycle cylinder is at least equivalent to that of the cylinders operating with the diesel process. This enables potential fuel savings and emissions reductions of about $8.3 \%$ in the studied scenario.
\end{abstract}

Keywords: Organic Rankine cycle, Marine diesel engine, Waste heat recovery, Piston expander, Novel configuration

\section{Introduction}

The production of mechanical energy and electricity using waste heat recovery (WHR) systems requires no fuel input and associated $\mathrm{CO}_{2}$ emissions. For these reasons, the application of WHR systems have received much attention as a technology that can help to reduce emissions, that are commonly known to lead to global warming. Large ships are technically feasible candidates for

\footnotetext{
${ }^{*}$ Principal corresponding author. Tel.: +4553250303

Email address: ulrik.larsen@chalmers.se (Ulrik Larsen)
} 
the implementation of this technology. Motivation for doing so exists because the fuel expenses amount to about 30 to 55 percent of the ship operational costs [1] and because emission regulations are being tightened.

The idea of WHR for the use on ship combustion engines dates back to at least 1919 when the innovative Still engine was disclosed [2]. It utilised exhaust heat to produce steam that was expanded under the pistons to reduce the compression power and thereby increase the engine's efficiency.

The steam Rankine cycle (SRC) technology, for WHR, is now well established and advanced plants are used on the largest container ships, such as the Maersk Triple-E type [3]. Several major global players within the maritime industry [4-7] have proposed SRC combined cycle systems that promise efficiency gains of around 11-12\%. This number has been confirmed in theoretical studies, e.g., by Dimopoulus et al. [8], who presented a detailed study of the SRC system while considering various engine loads.

Recently, the organic Rankine cycle (ORC) for ship application has received significant attention in the scientific literature. Song et al. [9] presented a thermodynamic analysis of an ORC plant utilising both the engine jacket water heat and the exhaust gas and the conclusion was that such a plant is both technically and economically feasible. Yang and Yeh [10] presented a techno-economic study of an ORC using the same two heat sources. The authors found a number of suitable working fluid candidates and associated optimised values for the ratio of net power to equipment cost. Choi and Kim [11] investigated the potential of a dual-loop cycle for WHR on a large two-stroke engine, while considering realistic operating conditions. The authors found a potential for fuel savings of about $9.4 \%$.

The installation of energy saving technologies on board ships, such as a WHR unit, relies heavily on the cost-benefit aspect [12]. Prater [13] listed three prerequisites for the success of a given WHR technology: 1) minimal losses in the process of transporting the heat from the source to the conversion unit, 2) efficient vapour expansion, and 3) a limited system complexity.

Embracing these three items, a previous study by Conklin and Szybist [14] proposed a new engine cycle with integrated WHR. In this concept, two additional strokes were added to the conventional four stroke engine, in order to produce power by expanding vapour generated from the engine's waste heat. 


\begin{tabular}{|c|c|c|c|}
\hline \multicolumn{4}{|c|}{ Nomenclature } \\
\hline \multicolumn{2}{|c|}{ Acronyms } & $\dot{m}$ & Mass flow rate $(\mathrm{kg} / \mathrm{s})$ \\
\hline BDC & Bottom dead centre & $A$ & Flow area $\left(\mathrm{m}^{2}\right)$ \\
\hline CAD & Crank angle degrees & $A$ & Heat transfer area $\left(\mathrm{m}^{2}\right)$ \\
\hline EOI & End of injection & $C$ & Coefficient (-) \\
\hline $\mathrm{EVC}$ & Exhaust valve closing & $D$ & Diameter $(\mathrm{m})$ \\
\hline $\mathrm{EVO}$ & Exhaust valve opening & $h$ & Specific enthalpy $(\mathrm{kJ} / \mathrm{kg})$ \\
\hline FH & Fire hazard & $k$ & Ratio of specific heats (-) \\
\hline GWP & Global warming potential & $L$ & Lift (m) \\
\hline $\mathrm{HH}$ & Health hazard & $P$ & Pressure (bar) \\
\hline IMO & The International Maritime Organisation & $Q$ & Heat $(\mathrm{kJ})$ \\
\hline MCR & Maximum continuous rating & $R$ & Specific gas constant $(\mathrm{kJ} / \mathrm{kg}-\mathrm{K})$ \\
\hline ODP & Ozone depletion potential & $r$ & Inlet valve radius (m) \\
\hline ORC & Organic Rankine cycle & $s$ & Specific entropy (kJ/kg-K) \\
\hline $\mathrm{PH}$ & Physical hazard & $T$ & Temperature $\left({ }^{\circ} \mathrm{C}\right)$ \\
\hline SFOC & Specific fuel oil consumption & & \\
\hline SOI & Start of injection & $t$ & Time $(\mathrm{s})$ \\
\hline $\mathrm{T} / \mathrm{C}$ & Turbocharger & $U$ & Internal energy $(\mathrm{kJ})$ \\
\hline TDC & Top dead centre & $U$ & Overall heat transfer coefficient $\left(\mathrm{kW} / \mathrm{m}^{2}-\mathrm{K}\right)$ \\
\hline WHR & Waste heat recovery & $V$ & Volume $\left(\mathrm{m}^{3}\right)$ \\
\hline Greek & Symbols & $W$ & Work $(\mathrm{kW})$ \\
\hline$\alpha$ & Geometrical expansion ratio (-) & Sul & ipts \\
\hline$\Delta$ & Difference (-) & 0 & Stagnation property \\
\hline$\gamma$ & Reduced pressure (-) & $\mathrm{d}$ & Discharge \\
\hline$\psi$ & Relative valve opening (-) & $\mathrm{i}$ & In \\
\hline$\rho$ & Density $\left(\mathrm{kg} / \mathrm{m}^{3}\right)$ & $\operatorname{lm}$ & Logarithmic mean \\
\hline$\theta$ & Crank angle degree $\left(^{\circ}\right)$ & o & Out \\
\hline Symbc & & $\mathrm{v}$ & Valve \\
\hline
\end{tabular}


Table 1: Diesel engine specifications

\begin{tabular}{rr} 
Type & 12K98ME-C6 \\
Cylinders (-) & 12 \\
Bore (m) & 0.98 \\
Stroke (m) & 2.66 \\
Engine speed MCR (rpm) & 104 \\
Specified MCR (MW) & 68.52 \\
Turbochargers (-) & 3 \\
Turbochargers type (-) & High efficiency \\
Mean effective pressure (bar) & 18.2 \\
\hline
\end{tabular}

The present study introduces a WHR concept which aims at utilising a single cylinder in a multi-cylinder engine as expansion device for high pressure vapour, generated from waste heat using an organic Rankine cycle. The purpose of this arrangement, besides the reduction of fuel consumption and emissions, is to reduce the overall WHR plant capital cost by removing the need for the turbine, gearbox, generator and frequency converter components.

The objective of this study is to present a thermodynamic steady-state analysis of the mentioned concept at design point conditions. This includes the identification of optimised process conditions and of the potential power production.

Section 2 includes descriptions of the concept, the model and the optimisation approach. Results are presented in Sec. 3, discussion follows in Sec. 4 and Sec. 5 concludes this paper.

\section{Methodology}

The models presented in the following were programmed in the Matlab language (v.2015a) [15]. The Coolprop (v.5) [16] library was used to estimate organic Rankine cycle fluid properties.

\subsection{System description}

The general idea of the concept presented is to use one of the cylinders in a large ship engine as an ORC expander, instead of using a turbine. The aim is to save the fuel input of one cylinder while maintaining the originally rated main engine power output. The engine used in this study is the MAN 12K98ME 12 cylinder low-speed two-stroke diesel engine, see the main specifications in Table 1. This engine is used to power very large container vessels. 


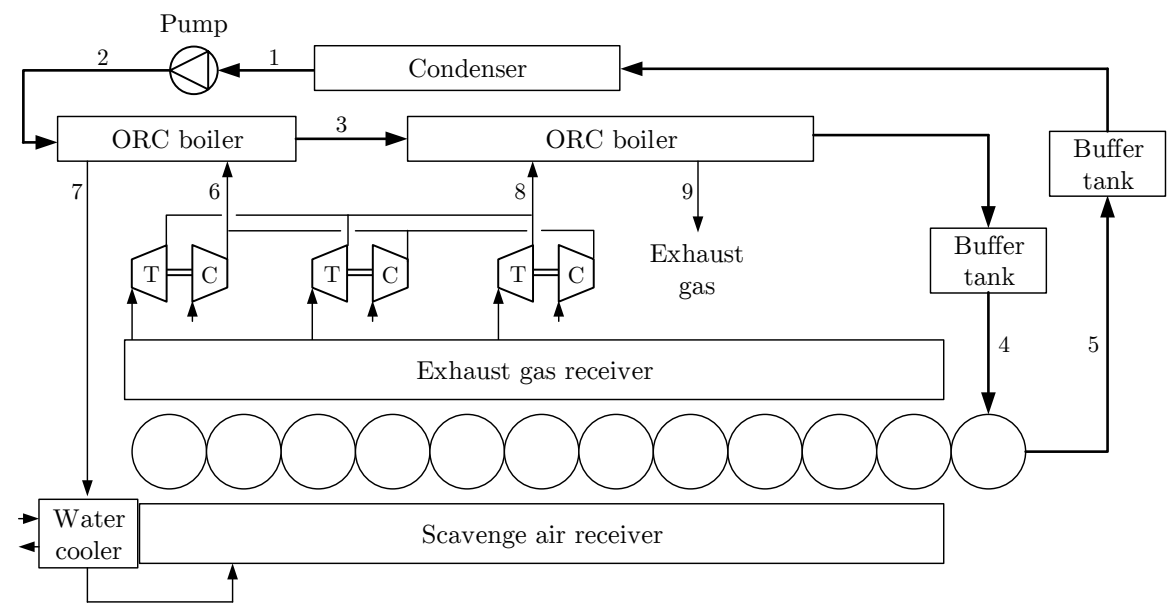

Figure 1: Sketch of the considered system. The bold lines indicate ORC working fluid flows.

A sketch of the system is shown in Fig. 1. The ORC pump elevates the working fluid pressure (1-2). The working fluid then enters the first boiler where it is pre-heated by heat from the engine turbocharger (T/C) compressor air, (6-7) and (2-3); if the evaporation pressure of the fluid and the amount of heat from the compressor air allows for it, the working fluid is partially evaporated in this boiler. If needed, the scavenge air is cooled further down in a seawater cooler before it enters the engine.

After expansion in the engine $\mathrm{T} / \mathrm{C}$, the main engine exhaust gases are utilised to further heat/evaporate and superheat the working fluid, (3) and (8-9). The fluid and process conditions, set by the optimisation variables, influence whether or not the working fluid reaches the boiling point during heating with the compressor air or with the exhaust gas heat.

The superheated fluid enters a buffer tank, which is not modelled, and from there it is injected into one of the engine cylinders at an appropriate time (4). Here, it expands to a low pressure before exiting the cylinder (5) to enter another buffer tank. Finally, the fluid is condensed using seawater as cooling media (1).

The organic Rankine cycle working fluid expansion process comprises the following five phases, see Fig. 2:

1. Compression starts when the exhaust valves are fully closed. Working fluid injection may start at the end of this stage because the valves take some time to fully open. The expected optimum time to start the injection is near the top dead centre (TDC) 
2. The TDC is reached and fluid is injected with fully open valves

3. Expansion with further injection of fluid

4. Expansion without injection until the bottom dead centre (BDC)

5. Exhaustion of the working fluid while the exhaust valve is open

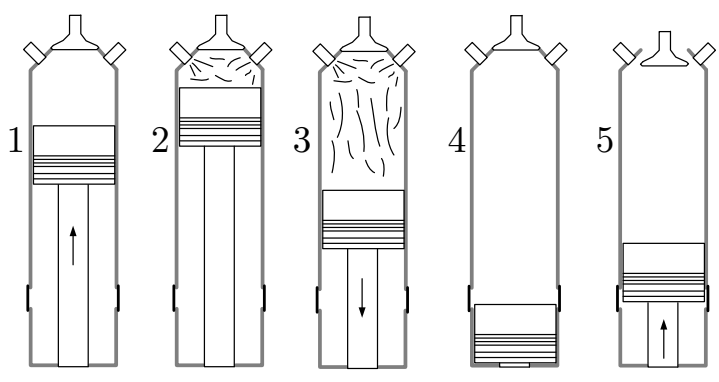

Figure 2: Sketch of the expansion process

Depending on the working fluid and process conditions, the pressure may be below the condensation pressure when the BDC is reached. In those cases some re-compression is needed (between stages 4 and 5) to avoid losses associated with fluid being sucked back into the cylinder from the condenser or buffer tanks when the exhaust valve is opened.

The available waste heat sets a limit on the working fluid mass flow rate; moreover, the engine speed is fixed by the relationship between the propeller and engine of the ship. Therefore, working with a fixed cylinder geometry may require unconventional valve timings that result in fluid injection late in the compression stage and re-compression before the exhaust stage.

\subsection{Modelling}

\subsubsection{Main engine}

The main engine cylinders that are operated with a regular combustion engine diesel cycle were simulated with a previously developed zero-dimensional model $[17,18]$. The model was validated against experimental data provided by MAN Diesel \& Turbo and data found in the literature. It can predict the main performance parameters at different loads and the effects on fuel consumption and NOx emissions due to engine tuning. Referring to Larsen et al. [17], the model prediction accuracies are within 0.5-2.0 \% for maximum pressure, 0.8-0.9 \% for power, 1.0-1.1 \% for exhaust temperatures and 0.9-4.0\% for specific fuel consumption. The cooling demand is under-predicted with $11.8-37.3 \%$. 
Briefly described the model consists of a two-zone combustion model, a double Wiebe function [19] heat release model, a heat transfer model using the Woschni correlation [20], and a NOx emissions model based on the extended Zeldovich mechanisms [21] with added reactions, as shown by Kilpinen [22]. The working gases were modelled using the Redlich-Kwong equation of state as according to the work of Danov et al. [23]. Friction losses were modelled using a correlation by Chen and Flynn [24].

The turbochargers were modelled using maps of the ABB A175 model provided by ABB. Due to confidentiality, the maps are not shown here, but the isentropic efficiencies of the compressors and turbines are well above $80 \%$.

Table 2 lists the performance characteristics at engine maximum continuous rating (MCR) (100 $\%$ load), as calculated by the model. The remaining system is also designed for this load.

\begin{tabular}{rr} 
Table 2: Engine performance characteristics \\
\hline Power $(\mathrm{kW} /$ cylinder $)$ & 5,593 \\
Compression pressure (bar) & 128.0 \\
Peak pressure (bar) & 140.8 \\
Fuel flow rate $(\mathrm{kg} / \mathrm{s}$-cylinder $)$ & 0.276 \\
Air flow rate $(\mathrm{kg} / \mathrm{s}$-cylinder $)$ & 17.0 \\
Fuel consumption $(\mathrm{g} / \mathrm{kWh})$ & 178.1 \\
Compressor outlet temperature $\left({ }^{\circ} \mathrm{C}\right)$ & 185.3 \\
$\mathrm{~T} / \mathrm{C}$ turbine outlet temperature $\left({ }^{\circ} \mathrm{C}\right)$ & 248.0 \\
Exhaust flow rate $(\mathrm{kg} / \mathrm{s}-\mathrm{cylinder})$ & 17.3 \\
\hline
\end{tabular}

\subsubsection{Piston expander}

The one engine cylinder which is used for ORC working fluid expansion was modelled by modifying the engine model described in the previous section. The combustion event was removed and more detailed models for the valve opening and the inlet and outlet flows were added (see the next section).

The basis of the model is a set of differential equations, that are solved over one engine cycle using the ODE15i solver. The following equation describes the overall energy balance of the cylinder:

$$
\frac{d U}{d t}=\frac{d W}{d t}-\frac{d Q}{d t}+\dot{m}_{i} h_{i}-\dot{m}_{o} h_{o}
$$


where $U, W, Q$ are internal energy, work and heat, while $t, \dot{m}$ and $h$ are time, fluid mass flow rate and specific enthalpy. Subscripts $i$ and $o$ are short for inlet and outlet. Here, $d W=p d V$ and the mass in the cylinder is $\rho V ; T, p, V$ and $\rho$ are, temperature, pressure, volume and density.

The friction loss was assumed to be the same as was calculated for the diesel process cylinders and the heat loss in the ORC expander cylinder was assumed to be insignificant. This seems reasonable because the cylinder liner temperature may be close to that of the diesel cylinders due to high conductivity of the cylinder material, i.e., about $175^{\circ} \mathrm{C}$, and the average working fluid temperature is about the same temperature. It is noted that this temperature depends on whether or not the cylinder is cooled actively. Further studies may investigate how these assumptions affect the results.

\subsubsection{Valves}

The two inlet valves and the two outlet valves were modelled as poppet valves as described by Heywood [25]. The fluid flows were assumed non-ideal by using a discharge coefficient (or flow coefficient), $C_{d}$, which is a function of the relative valve lift $L_{v} / D_{v} ; L$ is the lift, $D$ is the valve diameter and subscript $v$ is short for valve. The coefficient values were taken from a map of measured data [25], and depend on the valve geometry; in this case an isolated valve geometry was chosen because of the high efficiencies. The maximum valve lift was set to $0.25 D_{v}$ as recommended by Heywood [25].

The changing flow areas, as the valves open and close, depend on the valve lift which was modelled using a simple transition function provided by Wronski et al. [26]. The function was not derived from physical phenomena; however, with the correct timing it fits closely (confidential) valve lift curves provided by the engine manufacturer MAN Diesel \& Turbo. The relative opening $(\psi)$ was found by:

$$
\begin{array}{r}
\psi(\theta)=-\frac{3}{4}\left(\frac{1}{3} \cos ^{2} \phi \sin \phi+\frac{2}{3} \sin \phi\right)+\frac{1}{2} \\
\phi=\frac{\theta-\theta_{t}}{\Delta \theta} \pi
\end{array}
$$

where $\theta$ is the engine crank angle degree, $\Delta \theta$ is the time of transition (from open to close or vice versa) and subscript $t$ indicates the desired time of transition. $\Delta \theta$ was fixed to 10 degrees, a value that is reasonable considering real valve lift curves. The start of injection time was fixed 
to five degrees after valve closing time, to limit the amount of optimisation parameters, as it was found to be of minor importance. The number five was chosen (arbitrarily) to emulate a time gap that ensures that the valves are closed before injection starts.

The so-called curtain area $A_{c}$, equal to $\pi D_{v} L_{v}$, was chosen as reference flow area because of the simplicity of use. The mass flow rates in and out of the cylinder under choked flow conditions were found by:

$$
\dot{m}=\frac{C_{d} A_{c} p_{0}}{\left(R T_{0}\right)^{1 / 2}} k^{1 / 2}\left(\frac{2}{k+1}\right)^{(k+1) / 2(k-1)}
$$

where subscript 0 indicates the stagnation properties. $R$ is the gas constant and $k$ is the specific heats ratio and both were found using the Coolprop library. Choked flow conditions were assumed to occur when $p_{T} / p_{0} \leq[2 /(k+1)]^{k /(k-1)}$. Here $p_{T}$ is the pressure after the valve. The mass flow rates for non-choked flows were found with:

$$
\dot{m}=\frac{C_{d} A_{c} p_{0}}{\left(R T_{0}\right)^{1 / 2}}\left(\frac{p_{T}}{p_{0}}\right)^{1 / k}\left(\frac{2 k}{k-1}\left[1-\left(\frac{p_{T}}{p_{0}}\right)^{(k-1) / k}\right]\right)^{1 / 2}
$$

The choice of using poppet valves in the modelling should be seen as a first approximation. It is, from practical experiences with piston expanders, expected that significant efforts go into the detailed design of the valves.

\subsubsection{Boilers and pump}

The two boilers were modelled with basic mass and energy balance equations as described in Larsen et al. [27]. To assess the relationship between performance and heat exchanger requirements, mean UA values for each boiler were calculated using the well-known logarithmic mean temperature method for counter-flow heat exchangers:

$$
U A=\frac{\dot{Q}}{\Delta T_{l m}}
$$

$U$ and $A$ are the overall heat transfer coefficient and the heat transfer area, $\dot{Q}$ is the transferred heat and $\Delta T_{l m}$ is the logarithmic mean temperature. Since this method assumes linear temperature profiles, each boiler was discretised into 30 control volumes with an equal amount of heat transfer 
to approximate linear profiles. No heat or pressure losses were accounted for and all flows were considered having homogeneous properties.

The pump was modelled using an isentropic efficiency of $70 \%$. The minimum pump inlet temperature was assumed to be $40^{\circ} \mathrm{C}$ to keep condensers limited in size. The seawater temperature was assumed to be $25^{\circ} \mathrm{C}$.

The lower limit for the exhaust boiler outlet temperature was fixed to $160^{\circ} \mathrm{C}$, which is the minimum allowed for avoidance of sulphuric acid condensation. Simulations with boiler outlet temperatures higher than $160^{\circ} \mathrm{C}$ were found to lead to suboptimal power outputs, and this parameter was therefore not optimised further.

\subsection{Optimisation}

The Particle Swarm Optimisation and the Pattern Search methods, both included in the Matlab Toolbox [15], were used to screen a number of possible fluid candidates and to determine useful parameter values for the system. An objective function convergence criteria of $10^{-6}$ was used together with a swarm size of 2,000 individuals.

The optimisation variables are shown in Table 3. Zero crank angle degrees (CAD) is at the bottom dead centre (BDC). The valve timings in the table refer to the time when the valves begin their transition (from open to close or vice versa).

Due to the large variation in the properties of the screened fluids (dry, isentropic and wet types), and to not limit the optimisation procedure, relatively wide parameter ranges were allowed; thus, the ranges do not necessarily present feasible operational conditions. For example, a superheating approach of $1^{\circ} \mathrm{C}$ represents an extreme heat exchanger requirement. Another example is the maximum pressure, which in practice would be limited to a lower value than the critical pressure $\left(p_{c}\right)$ to avoid supercritical pressure in the pump, when taking into account the heat exchanger pressure drops.

The range of geometrical expansion ratios depend, in this case, on the dead volume of the cylinder as the remaining cylinder has a fixed geometry. To modify this volume, the piston crown can be fitted with shims and the entire cylinder head can be re-designed. High expansion ratios may be difficult to obtain in practice because of the need for room for the valve arrangement. For this reason, the influence of this parameter is investigated in the following section. 
Table 3: Optimisation variables

\begin{tabular}{rr}
\hline & Limits \\
\hline ORC evaporation pressure (bar) & $5-p_{c}$ \\
Superheating approach $\left({ }^{\circ} \mathrm{C}\right)$ & $1-150$ \\
Temperature difference $T_{7}-T_{2}\left({ }^{\circ} \mathrm{C}\right)$ & $5-100$ \\
Exhaust valve closing time $(\mathrm{CAD})$ & $90-179$ \\
Condensing temperature $\left({ }^{\circ} \mathrm{C}\right)$ & $40-120$ \\
End of injection time $(\mathrm{CAD})$ & $185-359$ \\
Exhaust valve opening time $(\mathrm{CAD})$ & $361-500$ \\
Inlet valve radius $(\mathrm{m})$ & $0.005-0.18$ \\
Geometrical expansion ratio $(-)$ & $2-50$ \\
\hline
\end{tabular}

\subsection{Model validity}

Due to the size of the machine, it is expensive and challenging to obtain test data to properly validate the ORC expander cylinder model. For verification, the results were compared with results made using a dynamic model presented in a previous study [28], see Table 4. The power outputs were calculated at optimised mass flow rates for the most promising fluid candidates (see the following section). The deviations are seen to range from 1.1 to 8.4 percent. The validity of the method used to simulate the expander is to some degree supported by the fact that it was derived from the validated diesel engine model; moreover, the approach is in general terms comparable to what can be found in the recent literature [29]. It is, however, still desirable to further validate the results.

Table 4: Comparison with dynamic model

\begin{tabular}{rrr}
\hline Fluid & Mass flow $(\mathrm{kg} / \mathrm{s})$ & Power, relative (\%) \\
\hline Cyclopropane & 70 & -2.2 \\
Isobutene & 67 & -1.1 \\
R245fa & 125 & -8.4 \\
R1234ze(z) & 132 & -4.8 \\
Cis-2-butene & 57 & -7.0 \\
\hline
\end{tabular}




\section{Results}

\subsection{Fluid screening}

Figure 3 presents the results of a first screening of the 104 fluids in the Coolprop library. Each fluid have been submitted to the optimisation algorithm for optimisation of the model variables listed in Table 3, with the objective of obtaining maximum power. Fluids with very poor performance (below 2,000 kW) are not shown. The dashed vertical line marks the nominal diesel engine power per cylinder for comparison. The results suggest that a number of fluids have the potential to produce as much power as the diesel cylinders.

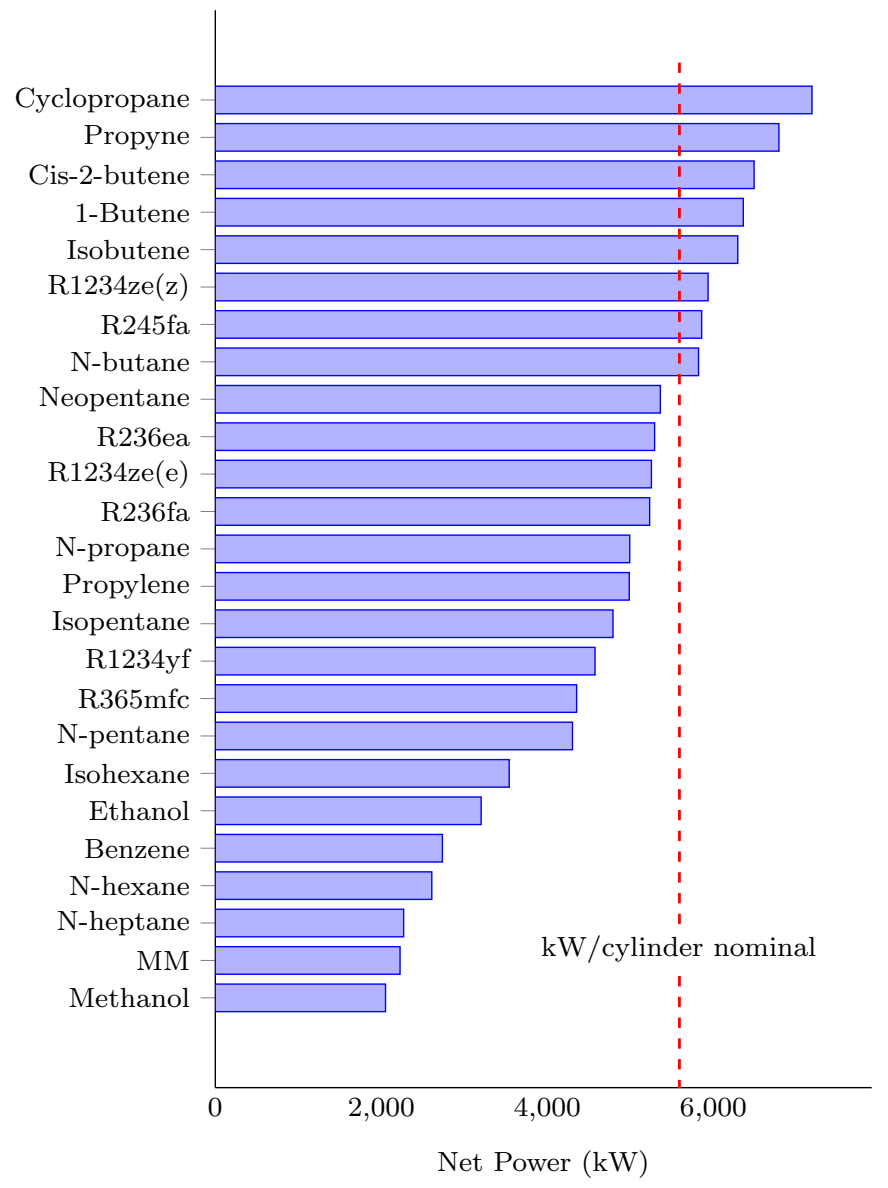

Figure 3: Optimised power for various fluids

From the state points of the optimised cases, shown in Fig. 3, the exergy flow rates were calculated as $\dot{m}\left(\left(h-h_{0}\right)-T_{0}\left(s-s_{0}\right)\right)$, with a $T_{0}$ of $298.15 \mathrm{~K}$, and $h_{0}$ and the specific entropy, $s_{0}$, found at $T_{0}$ and a pressure of 1 bar. See also Table 5 that presents the details of fluids, mass flow 
rates, pressures and temperatures. Figure 4 shows how the exergy flow rates at the inlet of the expander relates to the cylinder power, thus providing an insight into the exergy efficiency of the expansion process, as expressed by the ratio of exergy flow rate to power. It is seen that this ratio ranges from about 15 to 50 percent. Moreover, the fact that the largest exergy flow rate does not lead to the highest power output suggests that the boiler and the expander parameters are best optimised simultaneously. This supports the choice of optimisation approach applied in this study.

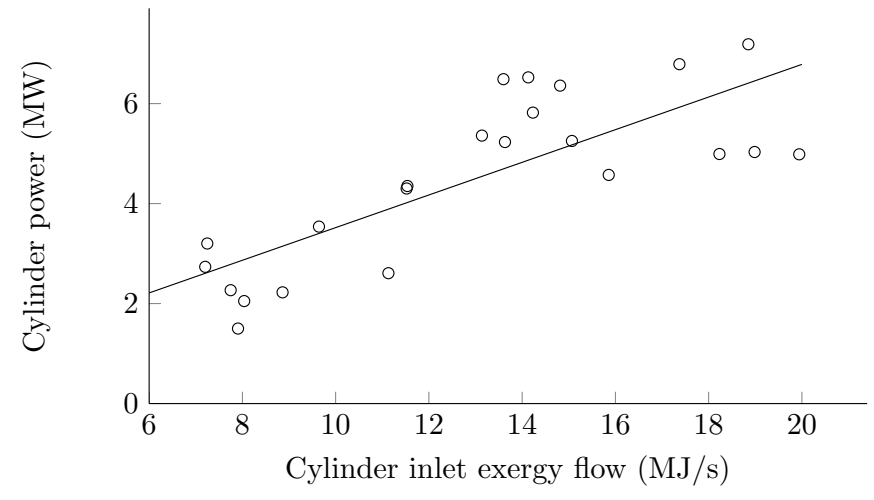

Figure 4: Optimised cylinder power in relation to the exergy flow from the boilers

The optimised parameters are shown in Table 5. Here $\gamma, \Delta_{i}$ and $\alpha$ are short for the maximum pressure in the process divided by the critical pressure, the fluid injection window and the expansion ratio. EVO, $r$, and $\Delta T$ are exhaust valve opening time, injection valve radius and the temperature difference between points (7) and (2), see Fig. 1.

It is evident that the optimised cycle maximum pressure, for most of the fluids, converges to the critical pressure, which is the maximum allowed in the optimisation. Despite the wide parameter ranges in the optimisation, it is seen that some of the optimised parameters do not differ much. The condensation temperature and valve timings converge towards what is expected, i.e., the minimum condensation temperature and an injection that starts near TDC.

Table 6 lists selected fluids that all have the potential to produce power at a level similar to the diesel process cylinders. Cyclopropane was selected for further analysis due to the superior power potential; R245fa was selected because it is a proven candidate for use in ORCs [10], and R1234ze(z) was selected since it is environmentally safe and non-flammable. The table lists values for global warming potential (GWP), ozone depletion potential (ODP), and fire, physical and health hazards (FH, PH, HH) as according to the HMIS classification [30]. The HMIS scale ranges from one to 
Table 5: Optimised parameters

\begin{tabular}{|c|c|c|c|c|c|c|c|c|c|c|c|}
\hline Fluid & $\gamma(-)$ & $T_{4}\left({ }^{\circ} \mathrm{C}\right)$ & $\Delta_{i}(-)$ & $E V O\left({ }^{\circ}\right)$ & $T_{1}\left({ }^{\circ} \mathrm{C}\right)$ & $\alpha(-)$ & $r(\mathrm{~m})$ & $\Delta T\left({ }^{\circ} \mathrm{C}\right)$ & $\dot{m}_{1}(\mathrm{~kg} / \mathrm{s})$ & $\bar{U} A_{1}(\mathrm{~kW} / \mathrm{K})$ & $\bar{U} A_{2}(\mathrm{~kW} / \mathrm{K})$ \\
\hline Cyclopropane & 0.998 & 200 & $177-231$ & 361 & 40 & 44.3 & 0.13 & 6 & 70 & 3474 & 385 \\
\hline Propyne & 1.000 & 229 & $177-230$ & 384 & 50 & 39.5 & 0.14 & 8 & 57 & 2947 & 574 \\
\hline Cis-2-butene & 0.946 & 242 & $177-230$ & 361 & 40 & 49.0 & 0.16 & 24 & 57 & 2506 & 1586 \\
\hline 1-Butene & 0.999 & 207 & $177-232$ & 362 & 40 & 49.8 & 0.18 & 9 & 71 & 2658 & 533 \\
\hline Isobutene & 0.998 & 220 & $177-232$ & 361 & 40 & 49.4 & 0.15 & 9 & 67 & 3314 & 634 \\
\hline R1234ze(z) & 0.997 & 205 & $175-232$ & 361 & 40 & 43.1 & 0.10 & 6 & 133 & 3793 & 570 \\
\hline $\mathrm{R} 245 \mathrm{fa}$ & 0.999 & 224 & $175-230$ & 361 & 40 & 47.2 & 0.09 & 7 & 125 & 4021 & 817 \\
\hline N-butane & 0.998 & 230 & $180-232$ & 363 & 40 & 50.0 & 0.11 & 11 & 61 & 4146 & 926 \\
\hline Neopentane & 0.999 & 204 & $176-230$ & 361 & 40 & 49.1 & 0.16 & 5 & 75 & 3321 & 1034 \\
\hline R236ea & 0.897 & 210 & $177-236$ & 366 & 40 & 49.9 & 0.18 & 6 & 148 & 2654 & 460 \\
\hline R1234ze(e) & 1.000 & 214 & $177-238$ & 361 & 40 & 50.0 & 0.18 & 5 & 131 & 1996 & 462 \\
\hline R236fa & 1.000 & 224 & $177-236$ & 361 & 40 & 49.3 & 0.18 & 6 & 143 & 2715 & 639 \\
\hline N-propane & 0.997 & 172 & $182-243$ & 362 & 40 & 49.0 & 0.16 & 5 & 80 & 1452 & 255 \\
\hline Propylene & 1.000 & 192 & $184-244$ & 375 & 40 & 43.9 & 0.18 & 6 & 76 & 1409 & 303 \\
\hline Isopentane & 0.905 & 200 & $177-221$ & 361 & 40 & 50.0 & 0.16 & 32 & 66 & 813 & 2476 \\
\hline $\mathrm{R} 1234 \mathrm{yf}$ & 1.000 & 180 & $177-245$ & 361 & 40 & 37.1 & 0.18 & 5 & 163 & 1380 & 278 \\
\hline $\mathrm{R} 365 \mathrm{mfc}$ & 0.611 & 194 & $176-243$ & 361 & 40 & 49.9 & 0.17 & 5 & 129 & 3865 & 923 \\
\hline N-pentane & 0.550 & 193 & $177-250$ & 362 & 40 & 50.0 & 0.16 & 9 & 70 & 3903 & 927 \\
\hline Isohexane & 0.574 & 201 & $175-234$ & 361 & 40 & 47.4 & 0.12 & 57 & 55 & 410 & 3381 \\
\hline Ethanol & 0.260 & 244 & $179-235$ & 362 & 59 & 49.8 & 0.16 & 99 & 20 & 82 & 1801 \\
\hline Benzene & 0.235 & 197 & $180-249$ & 361 & 57 & 49.9 & 0.16 & 100 & 40 & 69 & 3332 \\
\hline N-hexane & 0.295 & 213 & $177-288$ & 361 & 42 & 36.3 & 0.18 & 23 & 59 & 3754 & 4178 \\
\hline N-heptane & 0.356 & 209 & $179-242$ & 362 & 40 & 49.7 & 0.16 & 99 & 40 & 117 & 1882 \\
\hline $\mathrm{MM}$ & 0.519 & 215 & $176-238$ & 361 & 48 & 49.9 & 0.17 & 72 & 62 & 221 & 2875 \\
\hline Methanol & 0.081 & 247 & $184-333$ & 361 & 40 & 4.2 & 0.16 & 70 & 22 & 406 & 438 \\
\hline
\end{tabular}

four, where at hazard level four the fluid is life threatening in case of exposure(s); it may ignite spontaneously with air and is able to chemically react in an explosive manner. At hazard level one, the fluid may only cause irritation upon exposure; it will only burn if preheated and is chemically stable under normal conditions.

Table 6: Enviromental and safety factors

\begin{tabular}{rrrrrr}
\hline & GWP $^{100}$ & ODP & FH & PH & HH \\
\hline Cyclopropane & 1.1 & 0 & 4 & 0 & 2 \\
R245fa & 1030 & 0 & 1 & 0 & 2 \\
R1234ze(z) & 6 & 0 & 0 & 0 & 2 \\
\hline
\end{tabular}

Figure 5 presents the simulated diesel cycle process and the simulated ORC compression and expansion cycle process with two pressure-volume plots. It is the optimised case using cyclopropane as working fluid which is shown. The pressure development of the organic fluid expansion process is seen to be limited by the maximum allowed pressure of the ORC system.

The instantaneous power in the processes, equal to $\frac{1}{2} *\left(p_{i}+p_{i-1}\right)\left(V_{i}-V_{i-1}\right) /\left(t_{i}-t_{i-1}\right)$, can 

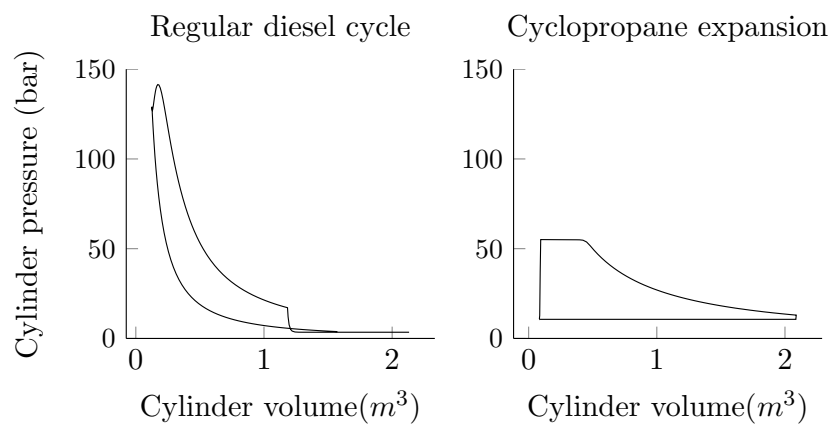

Figure 5: Pressure-volume diagrams

be seen in Fig. 6. These data are also derived from the optimised cyclopropane case. The diesel process has a large negative power during the compression stage, while the ORC expansion process looses power during the working fluid exhaust stage. It is also seen that the timings of the negative and positive powers are not entirely dissimilar; future tests may show whether or not this causes concerns related to the dynamic balance of the engine during operation. Note that the scavenging process is not modelled for the diesel process since the power required to scavenge is delivered by the turbochargers.
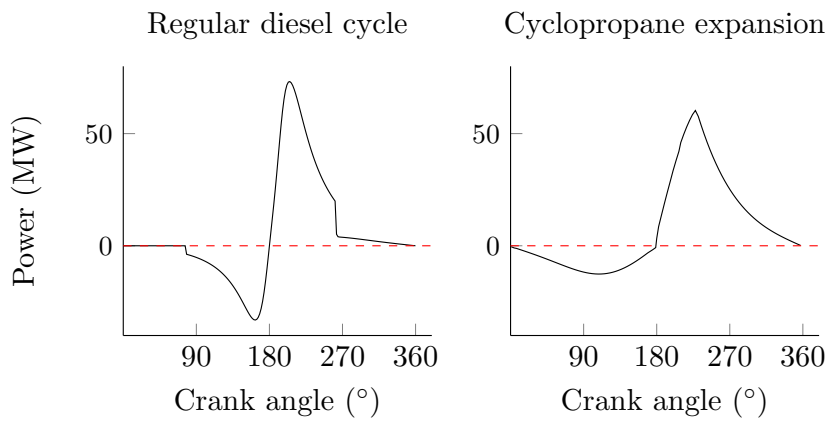

Figure 6: Instantaneous power

Because the parameter ranges in the optimisations were allowed to be wide, the optimum converges towards possibly very large heat exchangers in the boilers. The heat transfer temperatures for the optimised system with R245fa can be seen in Fig. 7 .

The hot and cold temperature profiles align very closely and it is expected that large heat exchangers are required under these conditions. Therefore, the sensitivity of the system performance to the boiler size, is reviewed in the following subsection. 


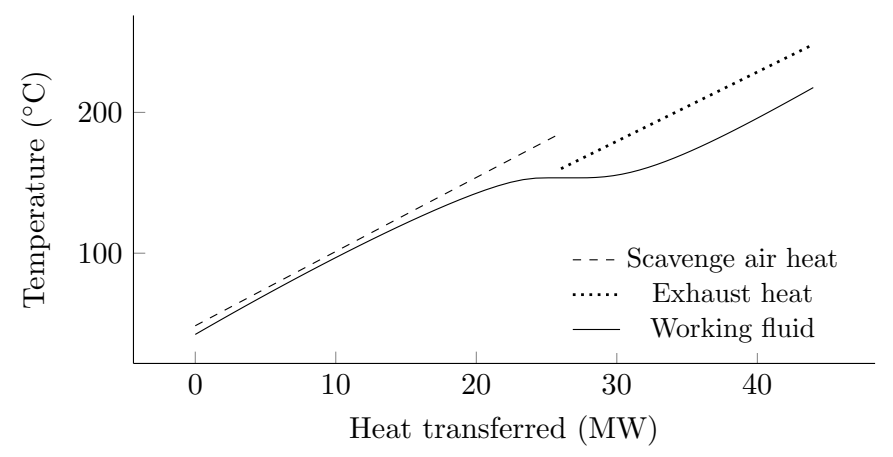

Figure 7: Heat transfer temperatures using R245fa

\subsection{Sensitivity to parameters}

In the following analysis, the model parameters shown in Table 3 were optimised using the approach described in Sec. 2.3, having the power output as the optimisation objective. Limitations on the total UA value for both boilers were set so that solutions with exceeding UA values were discarded. Pinch point temperature differences in the boilers were allowed to approach 1 degree K, thus allowing the UA value to be the limiting parameter. Compared to what is commonly found in the literature, e.g. Karellas et al. [31], $1 \mathrm{~K}$ is extreme and would lead to a relatively large heat exchanger volume. However, the application of the UA value as indicator rather than the pinch point has been used in other studies, e.g. Andreasen et al. [32].

In all cases, the optimisation algorithm converged towards the maximum allowed UA value and thus was the data for Fig. 8 produced. Since UA values higher than 5,000 kW/K did not yield higher power outputs, this value was chosen as an upper limit. The results are shown in Fig. 8 with a dotted line indicating the nominal engine cylinder power. The results show that, compared to the other two alternatives, using cyclopropane leads to higher power outputs for a given allowed boiler UA value. Figure 8 also suggests that it is possible to obtain the required power with UA values that are significantly smaller than the maximum 5,000. However, the steep decline in power at UA value limitations around 1,000 shows how strongly the power depends on the heat exchanger sizes.

The cycle pressure ratio is set by the optimisation algorithm with the evaporation pressure and condensing temperature, see Table 3 . The pressure ratio experienced by the piston expander is a function of the cylinder geometry, i.e., the expansion ratio, and the closing and opening times of the valves. All these three parameters are optimisation variables, see Table 3. To get an efficient 


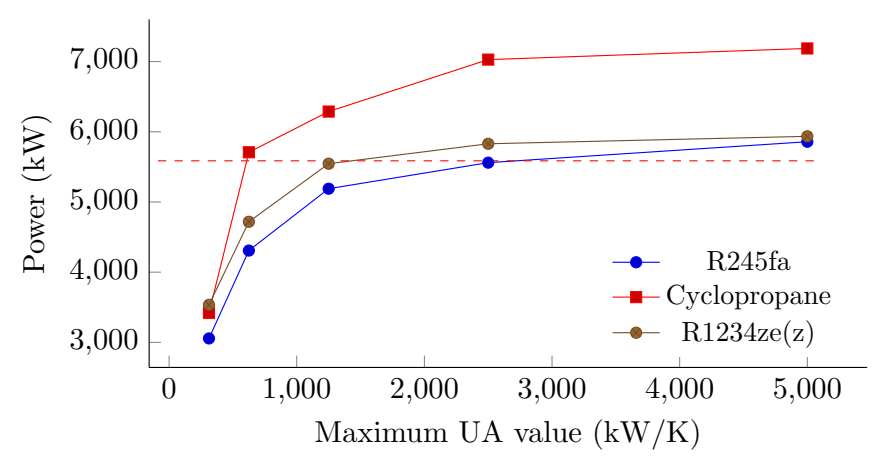

Figure 8: Optimised power in cases with limited combined boiler UA values

expansion process, the cycle pressure ratio and the expander pressure ratio must match, and this matching was therefore done by the optimisation algorithm in the search for high power and thereby high expansion efficiency.

Figure 9 presents the result of cases that are optimised for power while limiting the allowed range for geometrical expansion ratio of the cylinder, see Table 3. It is clear that the sensitivity to this parameter is not very significant within a range that may be assumed practically feasible. This is to some extent surprising since it is well known that the geometrical pressure ratio is of high importance with regards to cycle efficiency and thus cycle power. It is noted that the diameter of the inlet valves also influences the effective pressure ratio, since it influences the injection mass flow rate and thus the extent to which the pressure can be kept high during expansion.

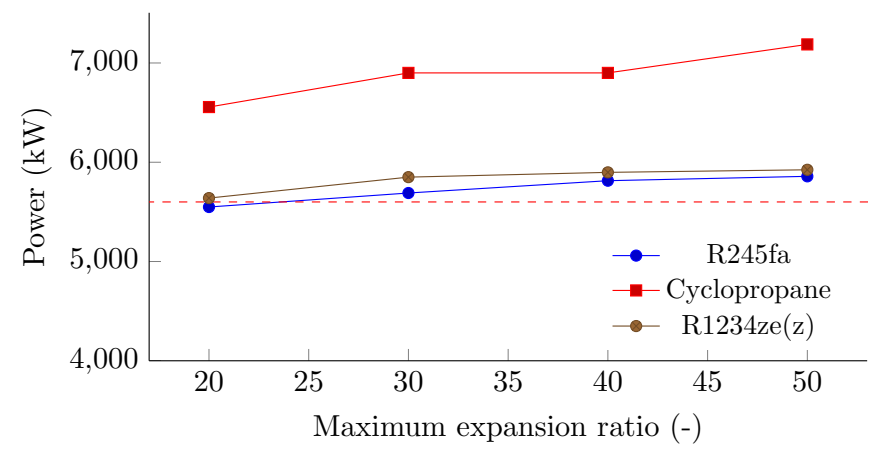

Figure 9: Optimised power in cases with limited geometrical expansion ratios

Thermal degradation of working fluids is closely related to the maximum temperature of the fluid [33] so it is of interest to limit the maximum temperature in the process. Figure 10 shows cases of optimum power when imposing limits from $150^{\circ} \mathrm{C}$ to $225^{\circ} \mathrm{C}$ and the tendency is that this 
constraint penalises the power output. Cyclopropane shows potential to produce power at a level of the diesel cylinders at all the investigated temperature limits.

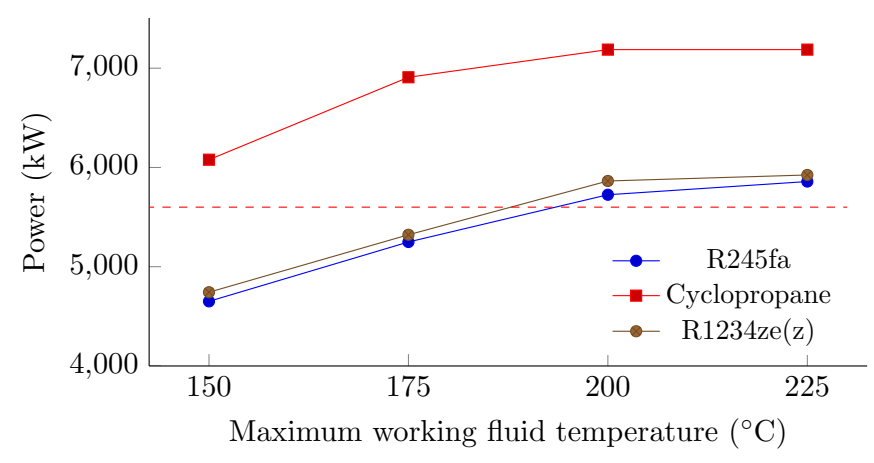

Figure 10: Maximum power in cases with limited maximum working fluid temperature

As mentioned, it is in the interest to keep the maximum process pressure at a certain level below the critical pressure. Figure 11 presents optimised cases when the pressure is limited to 80 to 95 percent of the respective critical pressures. The results suggest that the nominal power can be achieved while avoiding super critical pressures in the process.

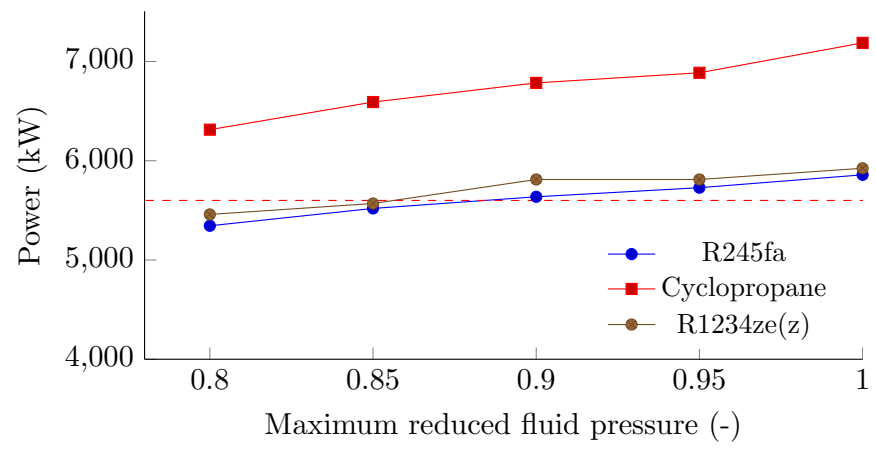

Figure 11: Optimised power in cases with limited maximum pressure

\section{Discussion}

The present study has a number of important limitations. Firstly, the load pattern of marine engines in large ships is not limited to full load, but includes also very low loads [34]. The results presented here are therefore considered a first step and a part-load analysis is the aim of a following study. The dynamics of the system may also be important to consider and is also targeted for a future study. 
Secondly, the modelling approach is simplified to be able to screen a large number of working fluids for potential, but not to study the process in detail. The possibility of neglecting important losses is therefore present. It is highlighted that the effects of having finite buffer tank sizes may play an important role. It is of particular interest to investigate to what degree the pressure varies during opening of valves and the consequences that follow. Also flow losses related to the design of the inlet and outlet valves deserve further attention.

The technical challenges before realisation of the concept are likely noteworthy. The two buffer tanks need to be large to accommodate the large amounts of gas flowing without too significant pressure drops during injection. Furthermore, for the implementation on a ship, the safety is paramount and the concept has inherent safety risks, especially if a flammable fluid is to be used.

Conversely, the concept may pose an interesting business case since it has other inherent advantages than the already mentioned, for example, the power produced is immediately available and will not have to be considered in the overall ship energy system configuration. Moreover, all emissions, including NOx, are reduced in proportion to one cylinder out of 12 . Due to the well known fuel consumption and NOx trade-off mechanism, the engine can therefore be tuned to obtain an even lower fuel consumption at the cost of a little more NOx.

Although not in the scope of the present work, heat for on board steam services has to be considered in the design of WHR systems for large ships. The present concept utilises all of the available high-temperature waste heat; however, there is a large amount of $100^{\circ} \mathrm{C}$ to $120^{\circ} \mathrm{C}$ heat available at the outlet of the (ORC) cylinder which may be combined with the available jacket water heat, for low pressure steam production.

Regarding the fluid screening method, it is a generally accepted approach to first exclude fluids on the basis of non-thermodynamic reasons and then run the thermodynamic computations. However, the following aspects motivated the choice of an approach that considered a large range of fluids. Firstly, the results suggest that fluids that are suitable for the present piston expander, are not the same as those found in the literature for an ORC with a turbine in a similar application. Instead, it seems that the best fluids are fluids that are usually found to be better for lower heat source temperatures [35]. Secondly, the limitations in the fluid selection in the present case study are diffuse since various technical measures can be taken to enable the use of fluids that would otherwise not be acceptable. For example, double walled piping can be used to minimise the fire 
hazard.

The relatively new fluid R1234ze(z) stands out as a promising fluid candidate, environmentally and in terms of safety which is of major importance for ship implementation. The safety measures needed on board are far more comprehensive for highly flammable fluids, such as cyclopropane, although not insurmountable; for example, methane is routinely used as a fuel on large ships. In addition, as Petr et al. [36] found in a recent study, R1234ze(z) has in ORC applications lower viscosities and similar thermal conductivities compared to R245fa, thus having potentially better heat transfer characteristics. A study by Longo et al. [37] confirms this in an experimental study, finding that R1234ze(z) has much higher heat transfer coefficients than other alternatives in high temperature heat pump applications. These properties may results in smaller heat exchangers, in particular the condenser where the working fluid heat transfer coefficient is relatively more important than in the boilers.

In the shipping world it seems commonly recognised that the capital cost of a WHR system is the main barrier to the installation; according to Lemmens [38] this is also the case for ORC installations outside of shipping. Lemmens [38] examined the literature about the cost of ORCs and, based on this work, the installed cost of an ORC, of the size as the one examined in the previous sections, is at least 11 million Euro (2013). The expected inaccuracy of this number is about $+/-30 \%[38]$.

With the presented concept, the plant costs may possibly be halved, compared to a conventional ORC plant, due to the lower number of components. Lemmens [38] reported that the expander and generator constitute more than half of the price, and similar numbers are found in other recent works [39].

\section{Conclusion}

Based on the presented results it is concluded that one cylinder in a 12 cylinder two-stroke marine diesel engine can, in theory, successfully be converted into an ORC expander. Since the waste heat alone powers one cylinder out of 12 , fuel is not needed for that cylinder and this contraption will thus lead to direct fuel savings and emissions reductions of about $8.3 \%$ (or 1/12) at a full load design point.

Numerous ORC working fluids are able to deliver power equivalent to the nominal diesel engine 
cylinder power, although with a different pressure/power development. R1234ze(z) appears to be a very suitable working fluid candidate for the use on a ship, with R245fa as an alternative with about the same performance. Cyclopropane leads to the most power but is more problematic for ship applications due to a very high flammability.

A sensitivity investigation of key system design parameters suggests that the power does not suffer significantly from reduced maximum pressure, maximum temperature and expansion ratio; however, large reductions in heat exchangers sizes does reduce the potential power significantly.

With the studied concept, a brief economical assessment suggests that an ORC can be installed for about half the capital cost, thus presenting a potentially attractive business case.

Future work is identified in a number research topics for the concept, among those analysis of the part-load performance, dynamic behaviour, further validation of results and analysis of various losses.

\section{Acknowledgements}

MAN Diesel \& Turbo and ABB are hereby thanked for their contributions. Thanks is given to the DTU High Performance Computing team for doing the computations.

\section{References}

[1] Kalli J, Karvonen T, Makkonen T. Sulphur content in ships bunker fuel in 2015. Tech. Rep.; Ministry of Transport and Communications; Helsinki, Finland; 2009. Accessed 08/09/2013; URL Www.jernkontoret.se/energi_och_miljo/transporter/pdf/sulphur_content_in_ships_bunker_fuel_2015.pdf.

[2] Times TNY. New british engine - surpasses diesel. New York Times 19;Accessed: 01/10/2015; URL http://query.nytimes.com/mem/archive-free/pdf?res=9E04E0DD173AE03ABC4051DFB3668382609EDE.

[3] Engelstof M. Website of Maersk. 2014. Accessed: 01/10/2015; URL www.maersk.com.

[4] MAN Diesel and Turbo. Waste Heat Recovery System (WHRS) for Reduction of Fuel Consumption, Emissions and EEDI. Tech. Rep.; MAN Diesel and Turbo; Copenhagen, Denmark; 2011. Accessed 24/11/2015; URL http://turbomachinery.man.eu.

[5] Green Ship of the Future. Website of Green Ship of the Future. 2015. Accessed 27/08/2015; URL Ww. greenship.org/lowemissionconceptstudy/lowemissionbulkcarrierstudy/technologiesused/.

[6] Mitsubishi Heavy Industries . Mitsubishi Energy Recovery System for Container Vessels. 2015. Accessed 27/08/2015; URL www.mhi-global.com/products/pdf/mers.pdf.

[7] Shmid H, Weisser G. Marine technologies for reduced emissions. 2006. Accessed 27/08/2015; URL www .marineengineering.co.za.winhost.wa.co.za/technical-information/waste-heat-recovery.pdf. 
[8] Dimopoulos GG, Georgopoulou CA, Kakalis NM. Modelling and optimisation of an integrated marine combined cycle system. Novi sad, Serbia: Proceedings of ECOS 2011; 2011, p. 1283-98.

[9] Song J, Song Y, wei Gu C. Thermodynamic analysis and performance optimization of an organic rankine cycle (orc) waste heat recovery system for marine diesel engines. Energy 2015;82:976 -85. doi: http://dx.doi.org/10.1016/j.energy.2015.01.108.

[10] Yang MH, Yeh RH. Thermo-economic optimization of an organic rankine cycle system for large marine diesel engine waste heat recovery. Energy 2015;82:256 -68. doi:http://dx.doi.org/10.1016/j.energy.2015.01.036.

[11] Choi BC, Kim YM. Thermodynamic analysis of a dual loop heat recovery system with trilateral cycle applied to exhaust gases of internal combustion engine for propulsion of the 6800 TEU container ship. Energy 2013;:doi: 10.1016/j.energy.2013.05.017.

[12] DNV-GL . Energy Management Study 2015. Tech. Rep.; DNV-GL; Hovik, Norway; 2015. Accessed 01/10/2015; URL www.dnvgl.com.

[13] Prater DM. A dual cycle reciprocating engine. In: SAE Technical Paper. SAE International; 2000,doi: http://dx.doi.org/10.4271/2000-01-3070.

[14] Conklin JC, Szybist JP. A highly efficient six-stroke internal combustion engine cycle with water injection for incylinder exhaust heat recovery. Energy 2010;35(4):1658 -64. doi:http://dx.doi.org/10.1016/j.energy.2009.12.012.

[15] Mathworks Massachusetts US. Matlab R2013a. 2013.

[16] Bell IH, Wronski J, Quoilin S, Lemort V. Pure and pseudo-pure fluid thermophysical property evaluation and the open-source thermophysical property library coolprop. Industrial \& Engineering Chemistry Research 2014;53(6):2498-508. doi:10.1021/ie4033999.

[17] Larsen U, Pierobon L, Baldi F, Haglind F, Ivarsson A. Development of a model for the prediction of the fuel consumption and nitrogen oxides emission trade-off for large ships. Energy 2014;:1 - 11doi: dx.doi.org/10.1016/j.energy.2014.12.009.

[18] Scappin F, Stefansson SH, Haglind F, Andreasen A, Larsen U. Validation of a zero-dimensional model for prediction of NOx and engine performance for electronically controlled marine two-stroke diesel engines. Applied Thermal Engineering 2012;37(0):344 -52. doi:10.1016/j.applthermaleng.2011.11.047.

[19] Miyamoto N, Chikahisa T, Murayama T, Sawyer R. Description And Analysis Of Diesel Engine Rate Of Combustion And Performance Using Wiebe's Functions. Proceedings - Society of Automotive Engineers 1985;:77-88.

[20] Woschni G. A universally applicable equation for the instantaneous heat transfer coefficient in the internal combustion engine. SAE International 1967;doi:10.4271/670931.

[21] Merker G. Simulating Combustion: Simulation of Combustion and Pollutant Formation for Engine-development. Springer; 2006. ISBN 9783540251613.

[22] Kilpinen P. Optimization of a simplified sub-model for NO emission prediction by CFD in large 4-stroke marine diesel engines. Fuel Processing Technology 2010;91(2):218-28. doi:10.1016/j.fuproc.2009.10.001.

[23] Danov SN, Gupta AK. Influence of Imperfections in Working Media on Diesel Engine Indicator Process. Journal of Engineering for Gas Turbines and Power 2000;123(1):231-9. doi:dx.doi.org/10.1115/1.1339986.

[24] Chen SK, Flynn PF. Development of a single cylinder compression ignition research engine. 1965. doi: dx.doi.org/10.4271/650733. 
[25] Heywood J. Internal combustion engine fundamentals. McGraw-Hill series in mechanical engineering; McGrawHill; 1988. ISBN 9780070286375.

[26] Wronski J, Skovrup M, Elmegaard B, Risl H, Haglind F. Design and modelling of a novel compact power cycle for low temperature heat sources. 2012,Accessed 24/11/2015; URL https: //books.google.dk/books?id=gumvHDQmJDOC.

[27] Larsen U, Pierobon L, Haglind F, Gabrielii C. Design and optimisation of organic Rankine cycles for waste heat recovery in marine applications using the principles of natural selection. Energy 2013;(0):. doi: 10.1016/j.energy.2013.03.021.

[28] Wronski J, Oudkerk JF, Haglind F. Modelling of a small scale reciprocating ORC expander for cogeneration applications. ASME ORC 2nd International Seminar on ORC Power Systems, The Netherlands; 2013,.

[29] Wenzhi G, Junmeng Z, Guanghua L, Qiang B, Liming F. Performance evaluation and experiment system for waste heat recovery of diesel engine. Energy 2013;55:226 -35. doi: http://dx.doi.org/10.1016/j.energy.2013.03.073.

[30] American Coatings Association, Washington DC, United States . Hazardous Materials Identification System. 2012.

[31] Karellas S, Schuster A, Leontaritis AD. Influence of supercritical \{ORC parameters on plate heat exchanger design. Applied Thermal Engineering 2012;3334:70 -6. doi: http://dx.doi.org/10.1016/j.applthermaleng.2011.09.013.

[32] Andreasen J, Larsen U, Haglind F. Design of organic rankine cycles using a non-conventional optimization approach. In: 28th International Conference on Efficiency, Cost, Optimization, Simulation and Environmental Impact of Energy Systems. 2015,

[33] Angelino G, Invernizzi C. Experimental investigation on the thermal stability of some new zero ODP refrigerants. International Journal of Refrigeration 2003;26(1):51 -8. doi:http://dx.doi.org/10.1016/S0140-7007(02)00023-3.

[34] Guan C, Theotokatos G, Zhou P, Chen H. Computational investigation of a large containership propulsion engine operation at slow steaming conditions. Applied Energy 2014;130(0):370 -83. doi: dx.doi.org/10.1016/j.apenergy.2014.05.063.

[35] Wang D, Ling X, Peng H, Liu L, Tao L. Efficiency and optimal performance evaluation of organic rankine cycle for low grade waste heat power generation. Energy 2013;50:343 -52. doi: http://dx.doi.org/10.1016/j.energy.2012.11.010.

[36] Petr P, Raabe G. Evaluation of r-1234ze(z) as drop-in replacement for $\mathrm{r}-245 \mathrm{fa}$ in organic rankine cycles from thermophysical properties to cycle performance. Energy 2015;93, Part 1:266 -74. doi: http://dx.doi.org/10.1016/j.energy.2015.09.035.

[37] Longo GA, Zilio C, Righetti G, Brown JS. Experimental assessment of the low GWP refrigerant hfo1234ze(z) for high temperature heat pumps. Experimental Thermal and Fluid Science 2014;57:293 - 300. doi:http://dx.doi.org/10.1016/j.expthermflusci.2014.05.004.

[38] Lemmens S. A perspective on costs and cost estimation techniques for organic Rankine cycle systems. ASME IGTI ORC 2015; 2015, p. 1-10.

[39] Astolfi M, Romano MC, Bombarda P, Macchi E. Binary ORC (Organic Rankine Cycles) power plants for the 
exploitation of mediumlow temperature geothermal sources Part B Techno-economic optimization. Energy 2014;66:435 -46. doi:http://dx.doi.org/10.1016/j.energy.2013.11.057. 